Journal of Physics and Its Applications

Journal homepage : https://ejournal2.undip.ac.id/index.php/ipa/index

\title{
Improving water absorption time and the natural silk strength (Bombyx Mori) using atmospheric dielectric barrier discharge plasma
}

\author{
Zaenul Muhlisin ${ }^{1,2 *}$, Muhammad Adrian Lathif ${ }^{1}$, Fajar Arianto ${ }^{1,2}$, Pandji Triadyaksa ${ }^{1,2}$ \\ ${ }^{1}$ Department of Physics, Faculty of Science and Mathematics, Diponegoro University, Semarang, Indonesia \\ ${ }^{2}$ Center for Plasma Research, Diponegoro University, Semarang, Indonesia \\ ${ }^{*}$ Corresponding author: muhlisin@gmail.com
}

\section{A R T I C L E IN F O}

\section{Article history:}

Received: 22 March 2021

Accepted: 24 May 2021

Available online: 28 May 2021

\section{Keywords:}

DBD Plasma

Silk

Point-to-plane electrode

Fabric strength

Water absorption time

\begin{abstract}
A B S T R A C T
This researchaimed to obtain Dielectric Barrier Discharge plasma discharge characteristics with and without the placement of natural silkBombyx Mori on one of the electrodes. Furthermore, the strength and the water absorption time of the irradiated silk samples will be analyzed. Plasma discharge is generated by connecting electrodes of point-to-plane configuration with a sheet of glass inserted on the plane electrode at atmospheric conditions. The characterization of plasma discharge, either with or without the natural silk samples' placement on the plane electrode, was performed by increasing A.C.'s high voltage power source to reach arch discharge. Theelectrode spacing varied from $0.7 \mathrm{~cm}$ to $2.5 \mathrm{~cm}$ with a $0.3 \mathrm{~cm}$ increment. Sample irradiation was performed using cold plasma for 5,15 , and 30 minutes respectively. Placing or not placing the natural silk samples on the plane electrode will increase the plasma's discharge current and increase the high voltage. Moreover, increasing the distance between the electrodes and placing the sample on the plane electrode decreases the discharge current. Using Scanning Electron Microscopy, it was found that increasing plasma irradiation time on samples decreases the silk thread'sdiameterand shortening its water absorption time. The strength of irradiated fabric was reduceduntil 15 minutes of irradiation. However, at 30 minutes of irradiation, there was an increase in sample thickness compared to control samples.
\end{abstract}

\section{Introduction}

The textile industry's fabric perfecting process is performed to improve fabric properties before the public uses it. Nowadays,most of the perfecting processes involve the use of high-energy physics processes and waste-intensive chemical methods. Moreover, both sets of fabric-perfecting processes require lots of water in their operation [1]. Usingconventional technology, any treatment to help enhance certain fabric qualities, such as antibacterial capacity, heat resistance, and water absorption capability, needs large water volumes [2]. This fact is also actual for the perfecting of silk.

Therefore, there is the need for an alternative technology that allows less water and produces less waste. Plasma technology is recommended to provide possibilities of treating material surfaces effectively with even higher precision. Its use in textile involves the technique of etching (scalping of parent material), cleaning (getting rid of contaminants), activating (increasing surface energy), and layering (depositing functional thin films) [3].

The use of plasma technology for textile processing should meet certain conditions, including generating desirable material properties [3]. Modifications on textile due to irradiation with plasma include changes in natural properties such as improved hydrophilic and hydrophobic abilities, better adhesion for enhanced mechanical characteristics, improved capillary absorption, and increased surface area. Other improvements include better electrical properties that would allow for interaction with electronic devices and increased filtration to facilitate the separation of physical and chemical properties [3-6].

Plasma is an ionized gas generated both in a vacuum and at atmospheric pressure [7]. The textile industry uses several types of cold plasma, generated at atmospheric pressure, on its operation, such as Corona Discharge, Dielectric Barrier Discharge (DBD), Atmospheric Glow Discharge Plasma (AGDP), and Atmospheric Pressure Plasma Jet (APPJ) [8]. Generation of AGDP and APPJ plasma requires the use of noble gases, while plasma discharge from Corona Discharge and DBD is easier to generate by using ionized ambient gases $\left(\mathrm{O}_{2}\right.$ and $\left.\mathrm{N}_{2}\right)$ [7].

Under atmospheric conditions, corona discharges consist of positive and negative corona discharges. Positive corona discharge generates positively charged particles such as $\mathrm{N}_{2}^{+}$, while negative corona discharge generates negative ion particles such as $\mathrm{O}_{2}^{-}$ [7]. Both positive and negative plasma discharges have proven to provide improved water absorption 
and strength in natural silk. These improved properties result from impacts and interactions between plasma ions and silk [5-9].

In DBD, high voltage is applied between electrodes which a dielectric layer covers one or both electrodes. The dielectric layer's purpose is to rapidly terminate the arcs that form in the region between electrodes. The discharge consists of a series of rapid micro discharges [10]. This research elaborates on the effects of DBD discharge, i.e.,positive and negative ion particles, on natural silk (Bombyx Mori) in atmospheric conditionsrelated to water absorption and the strength of natural silk fabrics.

\section{Research Method}

The plasma chamber in atmospheric condition for this research was generated using a high voltage A.C. power source connected to point-to-plane electrodes. A high voltage A.C. power source allows variation of potential difference up to $25 \mathrm{kV}$. There were 100 point electrodes distributed evenly across a square, with each electrode separated $1.3 \mathrm{~cm}$ apart, with the plane electrode made of a metal sheet. Athree mm thick dielectric material made of glass is placed on top of the plane electrode. The potential difference was observed using a digital voltmeter CD771 connected through the SEW PD-28 HV probe to a high-voltage power source, while plasma current was observed using a clampmeter. A scheme of the research circuit is shown in Fig. 1.

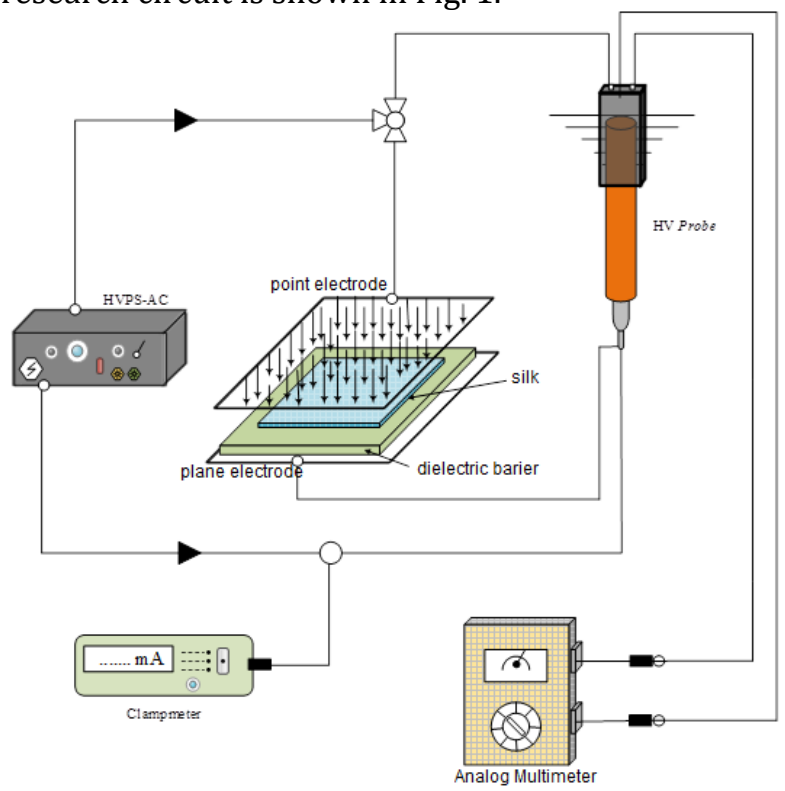

Fig.1: Scheme of the research instrument.

Characterization of plasma discharge in atmospheric conditions was made in order to obtain discharge work area. The atmospheric discharge was performed by gradually applying a potential difference to point-to-plane electrodesuntil maximum capacity or until a discharging arch was obtained (Fig. 2a). The point electrodes were made from stainless steel, and the plane electrode was made from copper. Point electrode Data collection was repeated for varied spacing between the point electrode and the plane electrode of $0.7 \mathrm{~cm}, 1 \mathrm{~cm}, 1.3$ $\mathrm{cm}, 1.6 \mathrm{~cm}, 1.9 \mathrm{~cm}, 2.2 \mathrm{~cm}$, and $2.5 \mathrm{~cm}$. Characterization of plasma discharge was also performed with Bombyx Mori natural silk in the discharge chamber (on top of the glass, as shown in Fig. 2b).

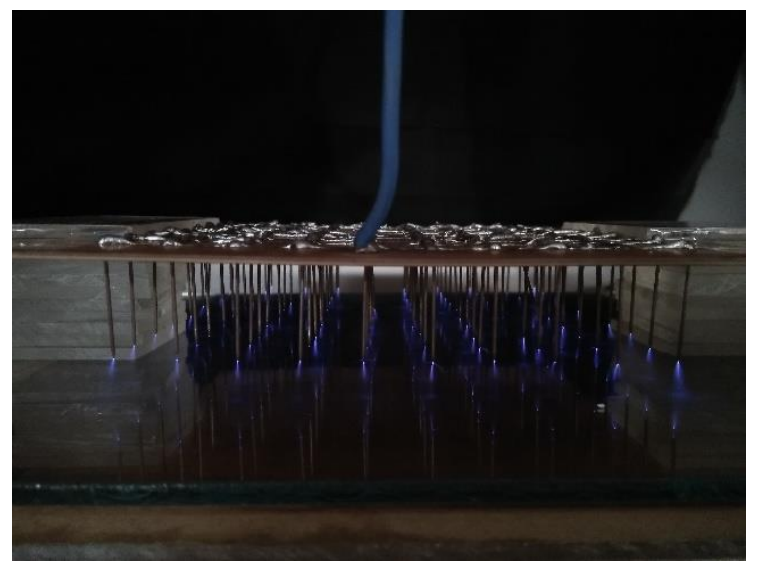

(a)

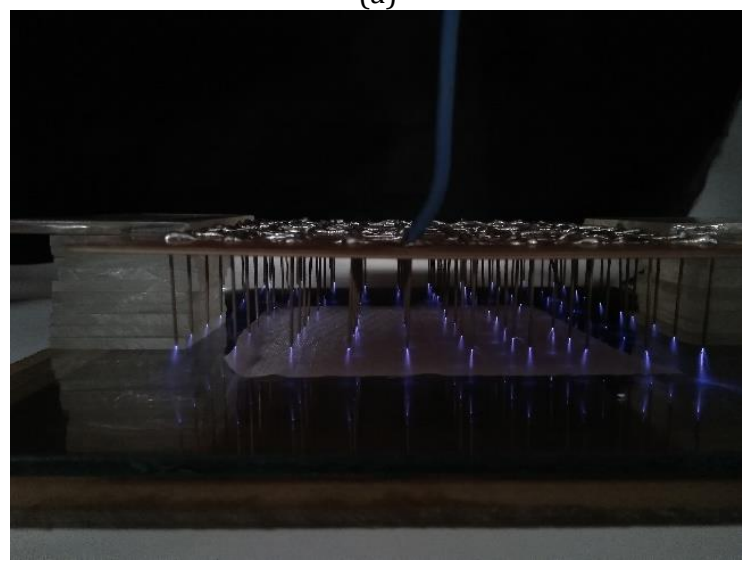

(b)

Fig. 2: Plasma discharge in atmospheric condition; (a) without and (b) with natural silk sample appears as a white fabric at the bottom of the needle electrodes.

Irradiation of Bombyx Mori natural fabric was carried out using cold plasma discharge, with the sample's tolerance against heat taken into consideration. The samples used are $10 \mathrm{~cm} \times 10 \mathrm{~cm}$ in area. Sample irradiation was performed at 5, 15, and 30 minutes discharge time, respectively. Changes in irradiated fabric properties were observed using water absorption test, tear test, and Scanning Electron Microscopy (SEM). The SEM is an electron microscope that produces an image of a sample, natural silk cloth, by scanning the surface with a focused electron beam with a magnification of up to a specific scale. The electrons interact with the atoms in the sample, producing various signals containing information about the sample's surface topography and composition.

A tear test was performed by expanding the sample and then applying a tear tension at the sample center until the tear was observable. The water absorption test was done by dropping one $\mathrm{ml}$ of water on natural silk fabric and measuring the time of the water droplets absorbed into the silk fabric. The measurement variation was made eight times in different fabric locations. The SEM test was conducted by observing the fabric structure on the SEM image with 1000x magnification to investigate the fabric's thread diameter and any microstructural impairment on the fabric. The SEM and tear tests were carried out at the Bandung Textile Center. 


\section{Results and discussion}

This research began by observing the characteristics of plasma discharge in the absence and presence of natural silk. Fig. 2 showedthe plasma discharge emission in atmospheric conditions without (a) and with (b) natural silk placement between the two electrodes that showed no visual difference in their glow brightness. The plasma's glow discharge on the needles' tip started to appear when initial ionization occurs and becomes brighter as the ion flows to the plane electrode. These flowing ions are alternating positive and negative ions as a result of the A.C. power source. In atmospheric condition, positive ions are $N_{2}^{+}$particles stemming from ionization, whereas negative ions are from $\mathrm{O}_{2}^{-}$Electron captures[5]. These particles are the ones that collide and interact with the natural silk samples.

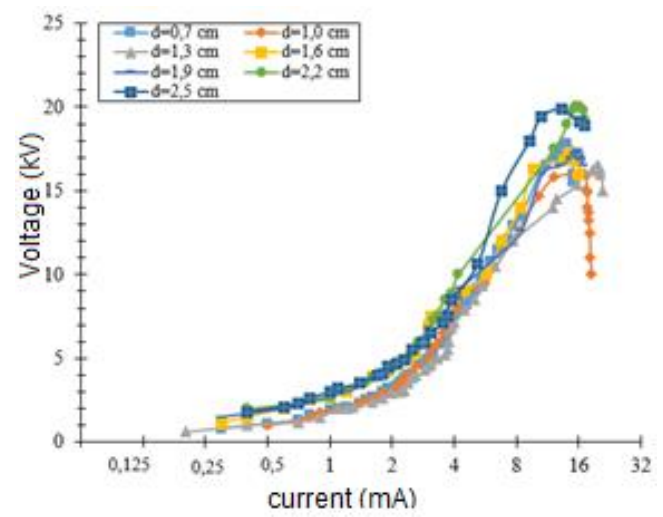

(a)

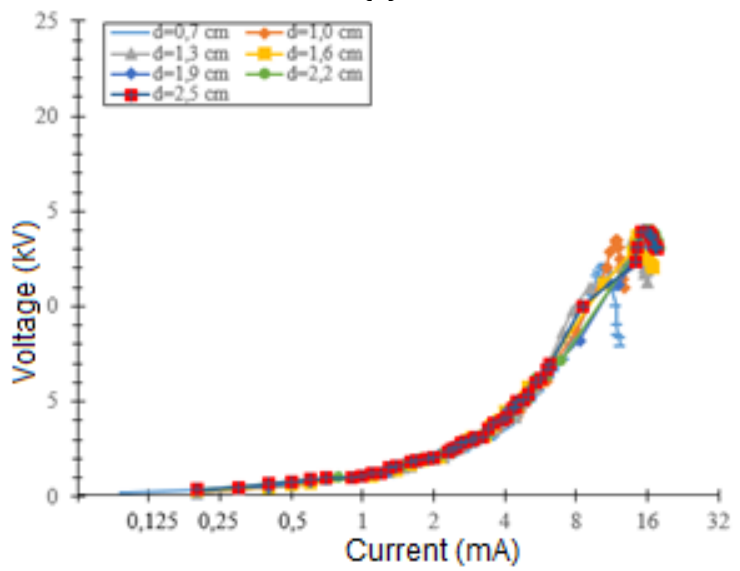

(b)

Fig. 3: Characteristics of potential difference and current of plasma discharge in atmospheric condition; (a) with and (b) without a sample(s) at various electrode spacing.

The plasma current pattern in atmospheric conditions was shown in Fig. 3, both with (a) and without (b) natural silk placement on the plane electrode. In both situations, the plasma discharges current started to be readable on the clamp meter in the order of micrometers when applying a $1 \mathrm{kV}$ potential. When adding the potential difference between electrodes, the plasma discharge intensity is gradually increased. The plasma discharge generated in this condition is known as corona plasma or cold plasma. This cold plasma stage ended when a spark and arc discharge appeared as the potential difference increases. The spark discharge is a transition from corona discharge to arc discharge. In contrast, the arc discharge is generated by double current flow with both positive and negative ions flow through electrodes simultaneously. When arc discharge occurs at high temperatures, it is also known as thermal plasma.

Natural silk placementon the plane electrode resulted in a lower discharge current in the plasma generation system. This trend applied to all variations of electrode spacing (d). This phenomenon was observed by Nugraha et al. in 2019 [5] on the radiation of positive corona plasma against natural silk. The explanation was that natural silk is a dielectric material that adds to a dielectric value of the space between electrodes.
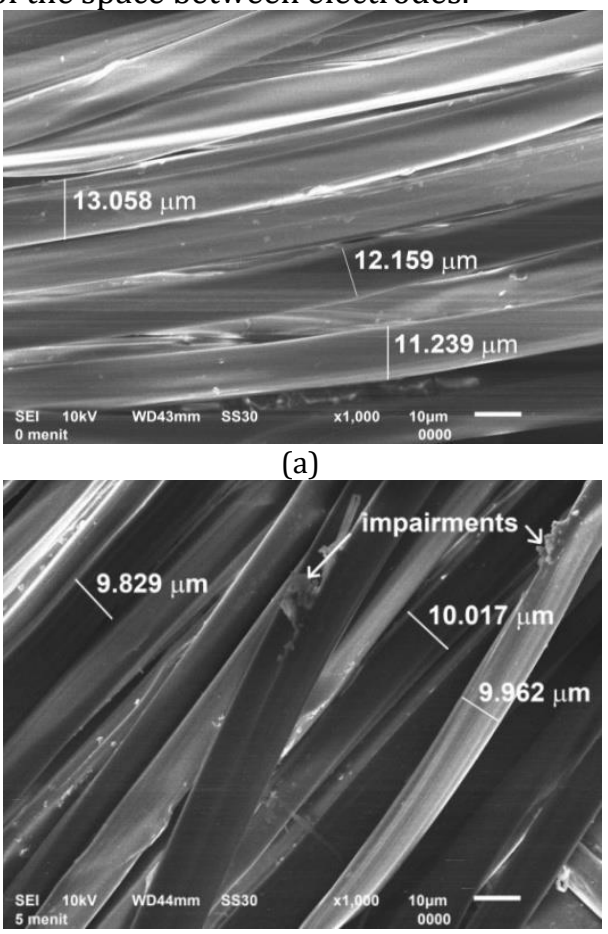

(b)

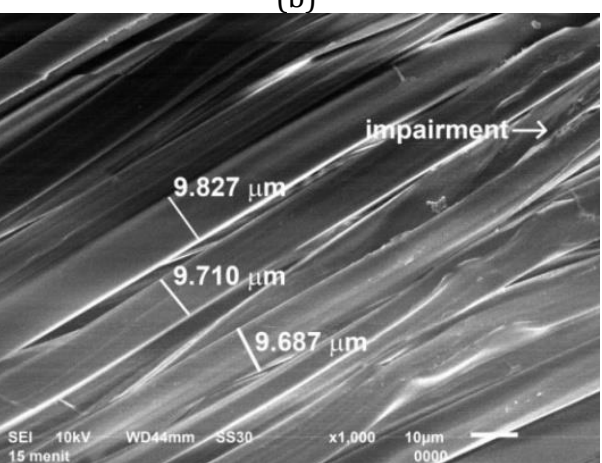

(c)

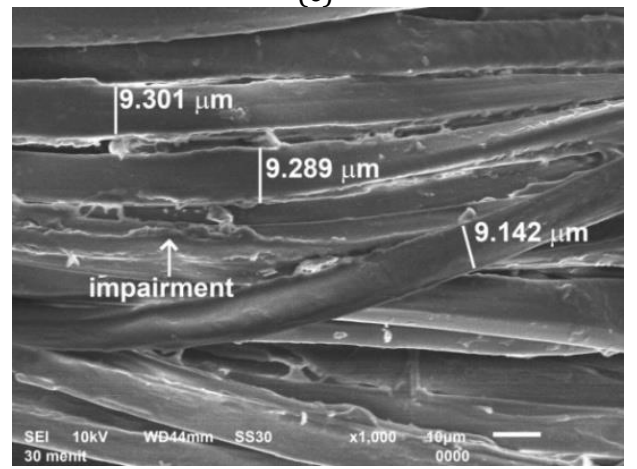

(d)

Fig. 4: Results of SEM imaging on natural silk; (a) nonirradiated, (b) irradiated for 5 minutes, (c) irradiated for 15 minutes, (d) irradiated for 30 minutes. 
Fig. 4 showed the effects of corona plasma discharge on natural silk. Figure 4 showed the image of natural silk samples; (a) non-irradiated, (b) irradiated for 5 minutes, (c) 15 minutes, (d) 30 minutes at $1000 \mathrm{x}$ magnification. These figures showed a shrinking thread formation from $12.152 \mu \mathrm{M}$ in diameter to $9.936 \mu \mathrm{M}, 9.741 \mu \mathrm{M}$, and 9.244 $\mu \mathrm{M}$ after being treated with DBD plasma for 5 minutes, 15 minutes, and 30 minutes, respectively. The thread size reduction was resulted from the collisions between ion particles and natural silk,causingan etching to occur. The bombardmentof the substrate with plasma species, i.e., $\mathrm{N}$ and $\mathrm{O}$, caused the breakdown of the silk fabric's covalent bonds and created an ablation that made the thread diameter reduced [10].

Other effects evident on the irradiated silk were tears and blisters. These were also the results of collisions between DBD ions and natural silk. More tears and blisters were observed with a more extended irradiation period. These impairments are also evident for polyester [6] andnatural silk [5] undergoing corona dischargeplasma treatment.These are the oligomers that were accumulated on the surface of the polymer. Oligomers are short fragments of polymers generated directly at the surface or migrate from the lower layers to the surface by diffusion.

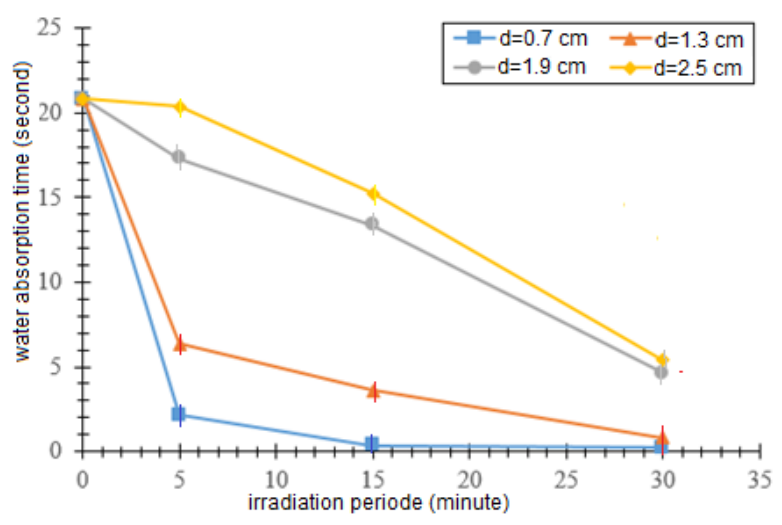

Fig. 5: Relationship between water absorption time (second) and irradiation period (minute) of the natural silk at different irradiation electrode distances.

Irradiation of DBD plasma on natural silk also alters the latter's strength, as shown in Fig. 6. Alteration in natural silk strength can be confirmed using SEM imaging, as shown in Figure 4. Natural silk irradiation using DBD plasma for 5 and 15 minutes reduced its strength by $728 \mathrm{kPa}$ and $727.8 \mathrm{kPa}$, respectively. The reduction happened because the fabric suffered blisters and cracks at its surface.

Fig. 5 shows the water absorption rate without irradiation and irradiation using DBD corona plasma at 5,15 , and 30 minutes, at electrode spacing of 0.7 $\mathrm{cm}, 1.3 \mathrm{~cm}, 1.9 \mathrm{~cm}$, and $2.5 \mathrm{~cm}$, respectively. It was clear that more prolonged irradiation time using DBD corona plasma on natural silk resulted in shorter water absorption time. Moreover, less space between electrodes speeds up this process further.The fastest water absorption time on natural silk fabrics was obtained at 0.22 seconds with the irradiation duration, and the electrode distance was 30 minutes and $0.7 \mathrm{~cm}$, respectively. The optimum absorption time was acquired because the surface of the irradiated silk fabric undergoes activation. Chemical surface modification was initiated by the radical reaction of plasma-activated gas or plasmagenerated U.V. radiation without layer deposition. In atmospheric pressure plasma, surface activation usually occurs with an oxygen-containing gas mixture such as air. Low-functionality surfaces become reactive by increasing the gas concentration containing oxygen or other polar groups on the plane electrode surface. Activation can also increase surface wettability whenthe polar surface groups increase surface energy [12-13].

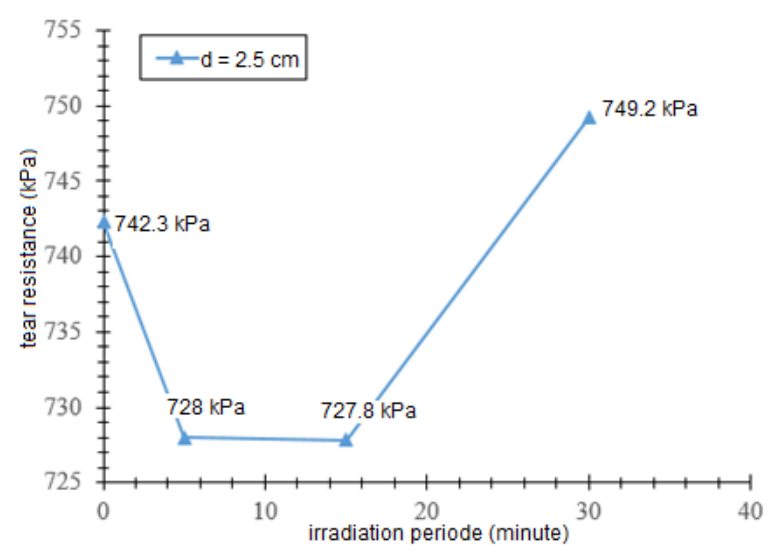

Fig. 6: Relationship between tear resistance $(\mathrm{kPa})$ and irradiation period (minute) of the natural silk.

Moreover, a decrease in the strength of the silk cloth can be caused due to U.V. penetration generated during the plasma radiation. U.V. radiation can cause various photochemical interactions with the bulk substrate silk fabric, resulting in impairment to chemical bonds and free radicals. This impairment may reduce the tear strength of the fibers [12].

However, it was found that increasing the duration of irradiation after 15 minutes results in a more robust fabric. The explanation is that more blisters and cracks allow for more surface friction whenever more significant pressures are exerted upon it.

\section{Conclusion}

This research shows that DBD plasma in atmospheric conditions affected the natural silk sample(s) condition. However, natural silk placement between electrodes also lowers the DBD plasma current. Meanwhile, a longer irradiation time using DBD plasma reduces the silk fabric'sthread diameter. The prolonged can cause even more shrinkage of the thread size in yarn diameter with more impairment at the fabric surface, creating a more accessible way to absorb water. Other than those, more prolonged irradiation also reduces water absorption time. It was also found that after 15 minutes of irradiation, the strength of natural silk increases.

\section{Acknowledgment}

The writer would like to thank UniversitasDiponegoro for funding this research 
via its Riset Pengembangan dan Penerapan (RPP)

grant number 233-119/UN7.6.1/PP/2020.

\section{References}

[1] M. Shabbir, S. Ahmed, and J. N. Sheikh (eds.) Frontiers of Textile Materials: Polymers, Nanomaterials, Enzymes, and Advanced Modification Techniques, Scrivener Publishing LLC309-333 (2020).

[2] K. K. Samanta, M. Jassal, and A. K. Agrawal, "Antistatic effect of atmospheric pressure glow discharge cold plasma treatment on textile substrates,"Fiber. Polym, 11(3), 431-437 (2010).

[3] R. Shishoo, Plasma Technologies for Textiles, $1^{\text {st }}$ Ed. (Woodhead Publishing Limited, New York,2007).

[4] Z. Muhlisin, D. Prastiwi, H. Darliawati, A. T. Sjaifuddin, F. Arianto, A.Y. Wardaya, and M. Nur, "Pembangkitan lucutan pijar korona negatif pada kondisi atmosfer dan pengaruhnya terhadap resapan air pada kain katun dan poliester grey," J.Are.Teks., 32(2), 8792 (2017).

[5] M. K. Nugraha, Z. Muhlisin, and P. Triadyaksa, P., "Karakterisasi plasma lucutan pijar korona positif pada bidang dan pengaruhnya terhadap kain sutra alam (bombyx mori) characterization of positive corona glow discharge plasma in atmospheric condition with multiple points to plane electrode configuration," J.Arena.Teks., 34(1), 25-34 (2019).
[6] U. N. Rizki, Z. Muhlisin, and F. Arianto,"Karakterisasi reaktor plasma berarus positif dengan konfigurasi elektroda titikbidang dan penerapannya pada kain polyester grey," In Young.Phys.J, 7(1), (2018).

[7] A. Fridman, "Plasma Chemistry,"(Cambridge University Press, New York, 2008).

[8] J. Peran, "Application of atmospheric pressure plasma technology for textile surface modification," Text.Res.J. 1-24, (2019).

[9] Z. Muhlisin, I. Rahmawati, F. Arianto, and P. Triadyaksa, "Characterization of negative corona plasma discharge reactor using pointto-plane electrode configuration in atmospheric pressure and its application in the treatment of woven natural silk," IOP Conf. Ser.: J. of Phys.: Conf. Ser.,1524, (2020).

[10] Z. Muhlisin, S. N. Hasan, U. Rizki, S. Tajibnafis and F. Arianto, "Characterization and effect of atmospheric corona plasma on grey knit polyester fabric characterization and effect of atmospheric corona plasma on grey knit polyester fabric,"IOP Conf. Ser.: J. of Phys.: Conf. Ser.,1217, (2019).

[11] L. Tian, H. Nie, N. P. Chatterton, C. J. Branfordwhite, Y. Qiu, and L. Zhu, "Applied Surface Science Helium/oxygen atmospheric pressure plasma jet treatment for hydrophilicity improvement of grey cotton knitted fabric,"Appl. Surf. Sci. J., 257, 7113-7118, (2011). 